\title{
The irresistible charm of the micro-foundations dogma or the overwhelming force of the discipline's hard core?
}

\author{
Thanos Skouras* \\ Emeritus Professor of Economics, Athens University of Economics and Business, Greece \\ Yiannis Kitromilides ${ }^{*}$ \\ Associate Member, Cambridge Centre of Economic and Public Policy, Department of Land Economy, \\ University of Cambridge, UK
}

\begin{abstract}
The appeal of the 'Micro-foundations' project, which requires that all macroeconomic propositions are reduced to or derived from microeconomic ones, is strongly supported by the considerable force of what Lakatos calls the discipline's 'hard core'. This is particularly so if this project is broadly interpreted as a way of giving precedence to microeconomics in unifying economic theory. Given the micro-theoretical nature of the 'hard core', questioning the Micro-foundations project is tantamount to confronting the 'hard core.' The paper questions the two most fundamental tenets of the 'hard core': maximization of utility and maximization of profit. It concludes that privileging micro over macro theory does not ensure sound foundations of the economics discipline and the Micro-foundations project makes little sense. Consequently, the search for consistency between microeconomics and macroeconomics should best be pursued in terms of a 'bridge' rather than a 'foundations' metaphor.
\end{abstract}

Keywords: micro-foundations, 'hard core', utility maximization, profit maximization, methodological individualism, fallacy of composition, 'unity of science', professionalization of economics

JEL codes: $A, A 1, A 14, B, B 4, B 41, D, D O 1$

\section{INTRODUCTION}

'Micro-foundations' is a relatively recent term in economics, with a life that hardly exceeds half a century. It is in fact encapsulating a metaphor, which ordains the relationship between microeconomics and macroeconomics. According to the metaphor, microeconomics constitutes the foundations of macroeconomics. It follows that macroeconomic theory without microeconomic foundations is unreliable and defective. The lack of foundations in any construction - theoretical as well as physical - makes it prone to collapse and, therefore, untrustworthy if not downright dangerous and worthless.

Metaphors tend to shape and direct thinking. They can be very powerful in framing the process of thought and enabling it to make connections and inferences on the basis of analogies. By the same token, they block (or at least make less likely or promising)

* We are thankful to the Bilbao conference participants and to an anonymous referee for constructive comments. We are, of course, solely responsible for any errors and omissions.

Received 31 August 2013, accepted 15 December 2013 
the exploration of possible alternatives outside their own framing of an issue. When they are not perfectly apposite, and especially if they harden into a dogma, they can become a barrier to fresh thinking and the development of a discipline. Consequently, the appropriateness of a metaphor is all-important.

Is the Micro-foundations metaphor an appropriate one or is it dangerous and misleading? According to King (2012), it is the latter. ${ }^{1}$ Moreover, he argues convincingly that the appropriate metaphor for the relationship between micro and macro is that of a bridge between the two rather than foundations of one by the other. Macroeconomics is not built on and does not need foundations provided by microeconomics; each one is constructed on separate foundations and what is required is a bridge between them.

King (2012) considers in some detail the history of the Micro-foundations metaphor and shows how this form of reductionism, which has counterparts not only in the philosophy of science but also in sociology, political theory, and history, has taken root in economics and rapidly hardened into a dogma. There are two serious objections to the Micro-foundations dogma which render problematic all reductionist projects in every scientific field: the principle of 'downward causation' and the 'fallacy of composition.' The first of these has to do with the effects that the whole has on the parts, which often tend to characterize complex systems. The whole or higher-level constructs may affect smaller units in ways which constrain, shape, or motivate their behavior. The structure of the whole is absent in the parts and this is what makes the whole more than the sum of its parts. It is also the reason why the behavior of the parts does not suffice to provide an explanation of the behavior of the whole. This is reflected in the second related principle, which is the 'fallacy of composition.' Here again, what is true and applies to the constituent parts cannot be aggregated and loses its validity when applied to the whole. The whole is characterized by emergent properties that are not contained in the parts and may be not only different but even negate the properties characterizing the parts, by standing in complete opposition to them. King lists a number of such fallacies in economics, the best known of which is the paradox of thrift. ${ }^{2}$

Nevertheless, the fascination exerted by the Micro-foundations project is not easy to overcome. The ideal of 'unity of science,' in which logical contradictions or inconsistencies do not exist and all knowledge is firmly based on the most fundamental elements, seems to be extremely appealing not only in economics but throughout the scientific community. The literature debating this matter is huge and extends beyond the philosophy and methodology of science to practically every field of scientific discourse. Its extent and complexity are such that it would be presumptuous for the ordinary economist to have strong, let alone dogmatic, views on this issue.

Our aim in this paper is to consider the Micro-foundations question in economics from a practical, common-sense point of view. In economics, the strength and tenacity of the Micro-foundations project seems to spring from a number of special factors, which tend to reinforce its universal primary attractiveness. The first three of these factors increase its appeal, acting like carrots, while the fourth has a dissuasive role and acts more like a stick. The three that enhance its appeal are adequately covered by King (2012), but the last one, to which he pays little attention, may be the most important. We will proceed as follows: in Section 2 we will discuss briefly the three factors that enhance the appeal of

1. In fact, anyone interested in the question of Micro-foundations, and especially if one is a heterodox economist, can do no better than read King's book, which has to be the starting point for any future dialogue in this field.

2. This, as Keynes has noted, was clearly perceived 300 years ago by Bernard Mandeville in his 1714 Fable of the Bees. 
the dogma; while in Section 3 we will examine the fourth factor, the disciplinary role and force of the 'hard core'. In Section 4 we consider the principal failings of the 'hard core'; and in Section 5 we present some conclusions.

\section{THE FACTORS THAT ENHANCE THE APPEAL OF MICRO-FOUNDATIONS}

The first factor is the strong predilection of the economics discipline, at least since the neoclassical revolution in the end of the nineteenth century, for methodological individualism. This is the notion that social phenomena result from the actions of individual agents and can be fully explained only by reference to the views and actions of individuals. ${ }^{3}$

Methodological individualism clearly implies the methodological primacy of microtheory. It follows that the reconstitution of the unity and integrated character of economic theory, which had been the proud achievement of neoclassical economics and distinguished the discipline from the other social sciences (until the appearance of macroeconomics), must respect this methodological desideratum. If economic theory is to be unified, this must be done in a way that preserves the primacy of micro-theory. Micro-foundations do exactly this: they assert the primacy of micro-theory in unifying economic theory. Establishing Micro-foundations means that all propositions in macroeconomics must be reducible to microeconomic propositions relating to the behavior of individual agents. It is this belief that King (2012) calls 'the Microfoundations dogma' and shows convincingly to be untenable. From this he draws the conclusion that neither can the primacy of micro-theory be established and justified nor is it essential for economic theory to be unified.

Though we are in agreement with King's (2012) conclusion, we think that his interpretation of Micro-foundations is unnecessarily strict. It is possible to show, we believe, that the Micro-foundations notion is untenable and undesirable, even on a less strict and ambitious interpretation of their aim. Such a demonstration, which we will attempt below, clearly strengthens the case against Micro-foundations: If they are indefensible on a less demanding interpretation, they are a fortiori untenable on a more stringent one. It also closes the escape route for the defense of Micro-foundations on the grounds that they never had such an ambitious aim (that is, of making all macroeconomic propositions reducible to microeconomic ones) and that King (2012) set up a straw man in order to easily demolish it.

The excessive strictness of King's (2012) interpretation becomes immediately apparent in the case of the post-Keynesians' reference to Micro-foundations. Weintraub (1956), who was the first economist to use the term in print, certainly did not claim that all macroeconomics is or should be reducible to microeconomics, and rejected this dogma. The same is true of Davidson's (1977) claim that the Micro-foundations for post-Keynesian economics have been provided by Marshall and Keynes, or Arestis's (1992) view that Eichner's (1976) model fulfills this task or, finally, those who argue that the Micro-foundations are contained in Kalecki. None of them has stated that all macroeconomic propositions in post-Keynesian economics are reducible to the microeconomic theory to be found in Marshall, Keynes, Eichner, or Kalecki. What they seem to be saying is that such microeconomic theory is consonant with and can easily be integrated within post-Keynesian economics.

3. The notion has obtained popular notoriety from Margaret Thatcher's proclamation that 'there is no such thing as society; there are individual men and women, and there are families.' 
King (2012) is, of course, quite right in pointing out that compatibility and ease of integration do not constitute foundations. A suitable metaphor might be that of a bridge or some similar structure, which highlights the assimilation potential of such micro-theory into post-Keynesian economics. The use of the Micro-foundations metaphor is unfortunate and plays into the hands of the dedicated supporters of methodological individualism. It is ideally suited to methodological individualism but quite inappropriate to anyone who denies the primacy of micro-theory and is only interested in the compatibility and even, to the extent that it is possible, the consistency between microeconomics and macroeconomics.

The second factor increasing the attractiveness of the Micro-foundations metaphor is related to the political ideology of classical liberalism, with which the discipline was associated practically from its beginnings. Classical liberalism emphasized the precedence of individuals and its main concern was the liberation of individuals from the shackles of the (mercantilist pre-modern) state. The Micro-foundations project is not just in accord with this ideology but has become its theoretical mainstay. General equilibrium theory is the highest achievement of the micro approach in full conformity with the Micro-foundations project. ${ }^{4}$ It demonstrates that perfectly competitive markets are capable, albeit under quite strict conditions, of generating a socially optimal configuration of relative prices. It thus vindicates Adam Smith's conjecture that such markets can operate like an 'invisible hand,' so as to bring about the socially most desirable allocation of products and resources. This is popularly interpreted in a vulgar fashion, as 'proving' the state's inability to improve on the outcomes of an economy consisting of perfectly competitive markets. ${ }^{5}$

The third factor enhancing the appeal of Micro-foundations springs from the gradual professionalization of economics and its establishment as an academic discipline in university studies. Given that physics was the most developed scientific field, economics aspired to imitate it by using its methods and approach for the study of society. This 'physics envy' promoted not only the use of mathematics in economics but also the emulation of physics, at least as it was popularly understood, in seeking more fundamental explanations of nature, at the 'micro' level of the atom or even below.

\section{THE FORCE OF THE 'HARD CORE'}

The fourth factor is also due to the professionalization of the discipline, but in its more mature stage. By the 1970s, when the Micro-foundations project (and name) had become firmly entrenched and effectively a dogma, economics was already established as an academic discipline throughout the world. Professionalization implied a canonization of the discipline's 'hard core,' in Lakatos's (2001) sense, ${ }^{6}$ together with the creation of

4. The claim that the general equilibrium approach is the highest achievement of economic theory has been canonized by Schumpeter (1954).

5. In contrast, macroeconomics was associated, from its much later beginnings in the late 1930s, with the malfunctioning of markets and the corrective potential of the state. This disaccord with the basic ideological tenets of the discipline was a handicap right from the start and may be a motive even today for seeking the replacement of macroeconomics by Dynamic Stochastic General Equilibrium modeling.

6. Lakatos's philosophy of science can be seen as a bridge from Popper to Kuhn. Starting from a Popperian background, Lakatos attempts to meet the criticism that Popper's falsificationist theory of scientific progress fails itself to pass the test of history. At the same time, he attempts to overcome the difficulty that Kuhn's theory of scientific progress has in explaining a paradigm shift on rational grounds. Though his success in this endeavor may be debatable (theory choice is not purged of social 
internal hierarchies. Such hierarchies or 'high priesthoods' were already in place by the 1970s, with the best American universities being at the top of the professional pyramid. What was taught there set the professional standard and became the required knowledge everywhere else. By the same token, training outside or contrary to the 'hard core' made a successful academic career practically impossible. Respect of the 'hard core', as specified and supervised by the 'high priests' was, therefore, a sine qua non for such a successful career. PhD students were quite aware of the high risk involved in being critical of the 'hard core,' and those wishing to pursue an academic career learned to practically identify it with doing economic 'science."

What is the discipline's 'hard core' and how does it affect the Micro-foundations project? Even if there is some haziness at the edges, it is clear that the 'hard core' includes certain tenets and methods, which define the academic practice of contemporary economics. A distillation of its essence is as follows. In economic explanation, there are two types of optimizing agents: individuals (mostly consumers but also workers) and firms. Consumers maximize utility (subject to a budget constraint) and firms maximize profits (subject to the technical conditions of production). On the basis of such maximization, demand and supply schedules can be specified for each product and these determine relative prices throughout the economy. The associated methods involve the construction of mathematical models, which formulate most questions as problems of maximization under constraints, and the generalized use of demand and supply schedules for the determination of prices, at the level both of markets (partial equilibrium) and of the whole economy (general equilibrium). These elements are closely interrelated, and they buttress and fortify one another. It might be argued that additional tenets and methods ought to be considered as part of the 'hard core,' but it can hardly be disputed that the ones above, which form an integrated whole, are undoubtedly included and cannot be dissociable from it.

It is evident that the 'hard core' consists essentially of micro-theory. Consequently, it has an affinity with, and cannot fail to favor the vision and aim of, the Micro-foundations project. There are, of course, reservations about the feasibility of the project, and these have been expressed by a number of prominent neoclassical economists (for example, Paul Samuelson and Milton Friedman, as noted by King (2012)). But even if these reservations are heeded by some economists, for many others the Micro-foundations project remains a desirable vision, which may be possible to achieve some day. In the meantime, a less strict and ambitious version of the Micro-foundations that seems more defensible can prove useful to the support of the 'hard core.' A defensible version of Micro-foundations may be promoted and effectively serve to shield the 'hard core' from fraying, as well as to impose discipline and restrain younger colleagues from straying out of the canonical pathway.

factors and the problem of incommensurability is not resolved), he introduces a more nuanced view of the scientific paradigm (which he calls a 'research programme'), by distinguishing between the 'hard core' and the 'protective belt.' We feel that Lakatos's concept of the 'hard core' is more expressive and less worn out than Kuhn's 'paradigm,' which is the obvious alternative concept. Moreover, the methodology espoused by the majority of the economics profession seems to be closer to Popper than to Kuhn; and Lakatos's work has attracted considerable attention among economists (see, for example, Latsis 1976). In any case, we have no strong views on the Lakatos vs Kuhn debate and it should be clear that, for the purposes of our paper, there would be no significant loss in meaning from the substitution of 'paradigm' for 'hard core'. Therefore, readers more familiar or at ease with the former are welcome to substitute the notion of 'paradigm' for that of the 'hard core.'.

7. This is still the case, and the 'hard core' today has as much (if not more) power as it had then. An example of how present-day prospective young academics experience the power of the 'hard core' can be downloaded and found at: economistsview.typepad.com/economistsview/2011/04/what-ilearned-in-econ-grad-school.html. 
This less ambitious interpretation of the Micro-foundations does not require that all propositions in macroeconomics are reducible to microeconomics. It requires instead that the central tenets and methods of the 'hard core' be respected in macroeconomics. Given that these are essentially micro-theory, the resulting macroeconomics may be taken to be dependent on Micro-foundations. In other words, the metaphor is changed almost imperceptibly, so that it may still apply. Even if macroeconomics cannot be fully constructible from or reducible to microeconomics, it is constructed by and is heavily dependent on material provided by microeconomics. The Micro-foundations project is that micro-theory should provide the main, if not all (as would be preferable), building blocks for the construction of macroeconomics. In this way, the Micro-foundations project becomes tantamount to showing the greatest possible respect for the 'hard core.' The metaphor is still applicable and acquires even more force since it serves a twin purpose: it not only directs and shapes thinking in the manner of any attractive metaphor, but it also disciplines thinking to respect the "hard core.' ${ }^{8}$

The Micro-foundations metaphor can be criticized, given this less strict interpret-

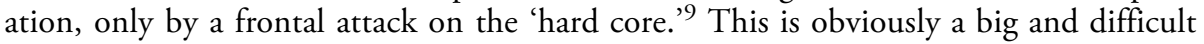
task, which is beyond our ability to bring to a fully conclusive end. In the rest of this paper, however, we will attempt to shake the confidence in the validity of the 'hard core.' If the 'hard core' is problematic and of doubtful validity, then the Microfoundations project loses its purpose. Losing trust in the 'hard core' removes the reason for privileging micro-theory over macroeconomics. As a result, King's position, that the appropriate metaphor is one of a bridge between micro and macro (a strong and reliable bridge that is still in need of construction), gains ground and can more easily become acceptable. Though our attempt may not lead to a complete rout of the Micro-foundations dogma, we expect that it will weaken it and, hopefully, make it clear why we find it unconvincing.

\section{THE FAILINGS OF THE 'HARD CORE' (OR BLUNTING THE DISCIPLINE'S LABRYS) ${ }^{10}$}

The 'hard core' has a number of failings and is unconvincing in various aspects. Here, we will examine the most important under two subheadings: first, the maximization of

8. It is thus undoubtedly an important constitutive metaphor, which determines what makes sense in the discipline's discourse and what does not. King (2012) is perfectly aware of the constitutive (rather than just pedagogical or heuristic) nature of the Micro-foundations metaphor for neoclassical economics and its role in delineating the Lakatosian 'hard core.' He even describes in a footnote the reaction of a 'very smart' young neoclassical theorist who could hardly distinguish the metaphor from the 'hard core,' finding the need for Micro-foundations evident and not requiring justification. An explanation for the smart young academic's reaction may be that he interpreted the Micro-foundations metaphor less strictly than King (2012), in the manner suggested above.

9. It may be argued that the 'hard core' is irrefutable by fiat, since the realism of assumptions is considered by Friedman (1953) and many others to be irrelevant, and only the predictions (which also involve the 'protective belt') are to be rigorously tested. Apart from the dubiousness of this methodological position (see Nagel 1963), there is the possibly more serious problem that, as Blaug (1980: xiii) has complained, 'economists do not practice what they preach' and hardly ever perform critical tests which may decisively refute any theory.

10. The labrys is the sacred double-headed axe of Minoan Crete. Metaphorically, the economics academic profession also has a sacred double-headed axe; its two heads are the 'hard core' and the microeconomics-based 'unity of science.' It should be made clear that the micro-theory with which 
utility; and second, the maximization of profits. We will appeal to work and results, not only of unorthodox schools of thought but also of prominent neoclassical economists. The latter are quite subversive of the 'hard core' and, presumably for this reason, ignored by the orthodoxy.

\subsection{Maximization of utility}

The use of this notion in economics has its origins in political philosophy and, more specifically, in J. Bentham's school of utilitarian philosophy, which argued that the aim of government ought to be the maximization of collective utility. It became a central notion in the neoclassical revolution, which explained prices as the outcome of the interaction between individual buyers maximizing utility and individual sellers maximizing profit in perfectly competitive markets. As it is clearly a crucial part of the neoclassical 'hard core,' it has been argued that it is futile to criticize it. ${ }^{11}$

Nevertheless, an unobservable concept that is held beyond question is not particularly convincing to anyone who is not compelled to share the neoclassical faith, especially since a new discipline - behavioral economics - has sprung up during the past quarter century in radical opposition to it. Based on the pioneering experimental work of Kahneman/ Tversky (1979; 1982), behavioral economics has amassed considerable evidence that decisively undermines utility maximization as a realistic basis for the explanation of human behavior. This new discipline initially appeared in business departments and, though it covers common ground with economics, it intellectually owes nothing to economic theory and everything to psychology and the experimental sciences. 'In fact, until about 1990, it was not uncommon to get a paper returned from a journal (usually after a delay of about a year) with a three sentence referee report saying "this isn't economics"” (Camerer et al. 2004: xxi). ${ }^{12}$ Even today, the vast majority of the economics profession has no understanding and little awareness of behavioral economics research. So far as the neoclassical 'hard core' is deemed worth defending, behavioral economics will not be seen as valid research but as a threat to 'economics.'

Maximization of utility for many economists is the exclusive basis for the derivation of downward-sloping demand curves (the 'law' of demand). ${ }^{13}$ Given the plausibility and

we are concerned does not represent all of microeconomics but the 'positive' (rather than normative) central body of theory, which forms part of the sacred axe. Game theory, the theory of auctions and other micro-based subjects, which are not relevant for the derivation of macroeconomics from microeconomics, are outside the scope of our analysis. Our critique is addressed solely to the microeconomics core, which can serve as the Micro-foundations of macroeconomics, rather than to the entire field of microeconomics.

11. For example, Boland (1981: 1036) considered it to be a metaphysical statement (his term for the 'hard core') and wrote thus: 'The research program of neoclassical economics is the challenge of finding a neoclassical explanation for any given phenomenon - that is, whether it is possible to show that the phenomenon can be seen as a logical consequence of maximizing behavior - thus, maximization is beyond question for the purpose of accepting the challenge.'

12. The authors are careful not to antagonize or threaten orthodox economists, who are institutionally in a much stronger position (presumably in the hope that they will overcome their distrust and become acceptable to economics departments), but it is difficult to see how their research could possibly be reconciled with the orthodoxy's 'hard core.'

13. Gustav Cassel was one of the few economists who treated downward-sloping demand curves as a 'primitive' empirical fact, rejecting the need for its explanation on the basis of utility maximization. See Stigler (1950). The relevance of consumer theory in this respect was also questioned by Mishan (1961). 
widespread evidence of a negative relationship between quantity demanded and price, its logical derivation from utility maximization (which is demonstrated often in great detail in all microeconomics textbooks) facilitates acceptance and reinforces belief in utility maximization. But this seemingly strong support of this part of the 'hard core' by another (the ubiquitous demand and supply model) is quite illusory. Leaving aside the problematic nature of the demand and supply construction, ${ }^{14}$ it is not true that the inverse relationship between quantity demanded and price requires acceptance of utility maximization.

In a brilliant and unintentionally subversive early article, Becker (1962) has shown that utility maximization and indeed rationality are redundant for the derivation of the law of demand. The so-called 'law' can be derived even if behavior is irrational and nonmaximizing. Thus, even on the assumption that behavior is based on habit or is random, the relationship between quantity demanded and price is an inverse one and the 'law' of demand still holds.

Becker (1962) shows that a negatively inclined demand curve holds not only in the case of consumption goods markets, when consumers are not rational, but also in markets for inputs demanded by irrational firms (that is, firms which do not maximize profits). In both cases, the reason is that there exist definite opportunity sets which are facing both types of irrational buyers and these opportunity sets are dependent on prices. The opportunity set facing consumers is determined by their income budgets, while the opportunity set for firms is given by the requirement that they avoid losses (that is, the set is limited to decisions which involve non-negative profits). A higher price for a good or input restricts its availability relative to others within the relevant opportunity set. As a result, the change in the opportunity set will render impossible certain previous decisions and will force some irrational buyers to reduce the quantity demanded, since the formerly desired higher quantity is no longer affordable.

Becker's (1962) demonstration that the 'law' of demand holds independently of utility maximization by rational agents is based on the heterogeneity of the irrational agents. It would not be possible to derive on the basis of a representative agent, in the manner of the Micro-foundations project, and shows that the properties of aggregates (which, in this instance, are product or input markets rather than the macroeconomy) cannot be obtained by the analysis of a representative individual. ${ }^{15}$ The importance of heterogeneity is further confirmed by another relatively neglected result by Hildenbrand (1994), who showed that the 'law' of demand is an effect of aggregation, which is ensured so long as the agents (that is, buyers) are sufficiently heterogeneous.

On the basis of the above results, it may be concluded that utility maximization is not necessary for the derivation of the 'law' of demand. But is it sufficient? Does utility maximization lead inescapably to an inverse relationship between price and quantity demanded? The so-called 'Sonnenschein-Mandel-Debreu theorem' (see Rizvi 2006) demonstrates that the general equilibrium model cannot be guaranteed to have a unique solution. This is considered to have far-reaching implications. One of these implications seems to be that utility maximization by rational individual agents does not assure the 'law' of demand holding in all markets. Consequently, utility maximization appears to be neither necessary nor sufficient for the derivation of the 'law' of demand.

14. See Skouras (1980).

15. The defects of any analysis based on the notion of a representative agent are shown clearly by Hartley (1997). The aggregation problems faced by representative agent models concern both consumption (Kirman 1992) and production (Fisher 1969). 


\subsection{Maximization of profit}

Maximization of profit, as the aim of business enterprise, is a notion that for a time seemed more secure than utility maximization, as the aim of consumers and workers. The reason may be that it was popularly held for longer and conformed to the beliefs of the wider public. A reinforcing factor was probably the coincidence of view held by professional economists, on the one hand, and those generally hostile to academic economics, on the other. This latter group includes all those adhering to every shade of Marxist and, more generally, anti-capitalist creed. Consequently, this unholy alliance strengthened conviction in the notion of profit maximization, dominated public opinion, and made it seem practically unassailable.

The first serious challenge to the notion was made by Berle/Means (1932). The authors noted that the rise of the modern corporation resulted in a separation of ownership from control. A new class of professional managers emerged, which took over control of the firm from the legal owners, the shareholders. The latter had no role in the actual decision-making and day-to-day running of the firm, which had become the exclusive prerogative of the managers. In addition, the owners tended to be numerous and dispersed, with very limited power to discipline the management and ensure that it acts in their own interest. The owners' interest may well be that the firm is run so as to maximize profit, but profit maximization may not necessarily be in the interest of the managers. It is not difficult to think of reasons why there can be divergence of interest between owners and managers.

The Berle/Means (ibid.) seminal work spawned a huge literature in the following years, which continues to the present. The best-known examples of theories about firm behavior, which argue that firms maximize an objective other than profit (exactly because this different objective best serves the interests of managers) are probably those proposed by Baumol (1959), Robin Marris (1963; 1964), and Williamson (1963; 1964). Baumol (1959) argues that managers' interests are best served when firms maximize sales, while Marris (1963) makes a case for the firm's balanced growth rate, which involves the maximization of the growth rate of the demand for the products of the firm along with the growth of its supply of capital. Finally, Williamson (1963) does not directly opt for a specific managerial interest but goes back to the orthodox micro principles. He thus claims that, just like any other individual economic agent, managers will attempt to maximize their utility and, therefore, the behavior of the firm will be dictated by whatever maximizes the utility function of the managers. He then proposes some plausible managerial interests to be included in the managerial utility function.

The separation of ownership from control is a real problem not only for the positive theory of the firm but also for the design of appropriate norms of corporate governance. The rapidly expanding recent literature regarding corporate governance takes as its starting point the recognition that management does not necessarily pursue the interests of the shareholders and implicitly rejects the view that firms actually maximize profits. The same position is prevalent in the relevant theoretical and applied work, which comes under the generic name 'the principal agent problem.'

But doubt about profit maximization does not concern only the question of whether profit is the objective that is maximized. It also concerns the question of whether maximization (not just of profit but of any other objective) is of relevance to what firms actually do. The first seed of serious doubt was sown by an empirical survey by Hall/Hitch (1939). They interviewed 38 business executives about their methods for setting prices and found that the majority of surveyed firms set their prices according to simple rules of thumb. Instead of equating marginal revenue to marginal cost, so as to maximize profit, 
they found that there is a strong tendency among business men to fix prices directly at a level which they regard as their full cost (Hall/Hitch 1939). More recent surveys confirm these findings and show that, contrary to what profit maximization dictates, the majority of managers take fixed and sunk costs into account when setting prices. ${ }^{16}$

This initial challenge was followed by behavioral models of the firm, which used what was known from empirical and experimental work about decision-making in organizations. Simon $(1955 ; 1959 ; 1964)$ paved the way with a seminal article, which introduced the notion of bounded rationality, and was followed by Cyert/March (1963), who presented the first fully developed behavioral theory of the firm. In their book, they argued that 'satisficing' rather than 'maximizing' drives managerial decision-making.

The empirical research and the use of empirically obtained knowledge from other sciences, which was advocated by the behaviorists as the way forward in understanding the behavior of firms, failed to make much of an impression on orthodox economics. ${ }^{17}$ It found followers mostly in business schools, as was the case with later behaviorist research that undermined utility maximization's pretence to explain human behavior. Moreover, no systematic effort was ever made to test the predictions of the profit maximization hypothesis against empirical evidence. For example, the prediction that a change in the tax rate on profits will not affect pricing does not seem to have ever been seriously tested.

It may not be surprising that profit maximization has not been subjected to strong tests, given its important position in the 'hard core.' After all, critical tests that conclusively refute any significant theory in economics are extremely difficult to find. But even the demonstration that a theory is inconsistent and logically implies patently implausible claims about the real world does not seem capable of invalidating crucial elements of the 'hard core,' such as the notion of profit maximization. A long-standing demonstration of this kind is witnessed in a remarkable and very brief article by Tibor Scitovszky (De Scitovszky 1943).

Scitovszky's (1943) focus is on the individual entrepreneur personally running his business rather than on managerially-run big corporations. It may be argued that departures from profit maximization associated with the latter cannot invalidate the results of general equilibrium analysis. This is because big corporations do not fit the specifications of firms operating under perfect competition, which is essential to general equilibrium analysis. But Scitovszky's (1943) owner-operated firm operating under competitive conditions is as close as possible to the archetypical firm of the general equilibrium model. Consequently, the implications of profit maximization by such a firm are of relevance and cannot be ignored by general equilibrium analysis. And these implications are 'rather special.' ${ }^{18}$

The main assumption on which Scitovszky's (1943) results are based is the reasonable one that the firm's output, receipts, and hence profits depend on the entrepreneur's activity or work time. He then argues that entrepreneurs, like consumers and workers, make decisions (in this case about how long to work) so as to maximize their utility, which is

16. See Al-Najjar et al. (2008).

17. This was despite the award of the economics Nobel Prize to H. Simon in 1978. The economics Nobel Prize awarded to D. Kahneman in 2002 may also prove to have little effect on the profession (especially as Kahneman is on record as stating that never in his life did he attend a single class in economics).

18. Scitovszky uses this euphemism and not only refrains from calling them implausible but even calls them 'very plausible.' A cynical view may be that this is the price a young immigrant economist (Scitovszky was under 33 years old when the article was accepted, had just enlisted in the US army, and was still 3 years away from his first academic appointment) had to pay for having a publication by a top journal of the profession. 
clearly what micro principles would dictate. He thus exposes an inconsistency in general equilibrium analysis, which posits unnecessarily and without justification a different motivation concerning the entrepreneurial firm from that of the consumers.

The entrepreneur's utility function might reasonably be taken to depend on profit (or net income) and leisure, which must be balanced against each other in order to maximize utility. Less leisure would normally require more profit as compensation while, beyond a certain point, defined by the entrepreneur's physical stamina and need for rest and sleep, no increase of profit or net income would suffice to compensate for any further reduction in leisure. It is then evident that profit maximization is an unlikely outcome and certainly cannot be guaranteed to emerge if entrepreneurs maximize utility. An entrepreneur who while maximizing utility also maximizes profit must have a strange utility function indeed. Such an individual needs no compensation in order to reduce his leisure; he has no interest in leisure and is only interested in profit. Since he gets no utility from leisure and all his utility comes from profit (which can only increase if he works more), he is constantly in danger of working himself to death. ${ }^{19}$

Despite the contorted way that Scitovszky (1943) presents his conclusions and his unwillingness to criticize the notion of profit maximization, ${ }^{20}$ it should be evident that his analysis is destructive to the neoclassical 'hard core.' A straightforward interpretation of his results is that: (1) they are inconsistent with the basic assumption of micro analysis to assume profit maximization in the case of small owner-run firms; and (2) if this is corrected and utility maximization is assumed instead, it is implausible that profit is maximized. Consequently, the choice is between inconsistency and implausibility. In any case, the damage to the notion of profit maximization is considerable. Not only is there strong theoretical and empirical evidence that profit maximization does not fit big corporations controlled by managers and operating under oligopolistic conditions, but also it is inappropriate for small owner-run firms operating under competitive conditions. Since these latter are one of the two types of economic agents on which the general equilibrium model relies, the logical demonstration that assuming profit maximization in their case is either inconsistent or implausible is a further serious blow to general equilibrium analysis.

\section{CONCLUDING COMMENTS}

It has been argued that the appeal of the Micro-foundations metaphor in economics is strongly supported by the considerable force of the 'hard core.' This is especially the case if the Micro-foundations metaphor is interpreted in the sense of respecting the essentially micro-theoretical nature of the 'hard core' and relying, to the greatest possible degree, on its basic tenets and methods in the construction of macroeconomics. It does not then suffice to show that all macroeconomic propositions cannot be constructed from or reduced to microeconomic ones, as this strict interpretation of the metaphor tends to miss the point and motivation of the Micro-foundations project. The project

19. Scitovszky (1943) muddies the water by unnecessarily complicating the relevant diagram and arguing that the strangeness of the required utility function consists in its implication of a constant marginal utility of money or, even more bizarrely, of a zero income elasticity of supply of entrepreneurship. He then glorifies the single-minded interest in profit and absolute disregard for leisure as the essence of the puritan ethic, which extols the virtues of frugality and industry. 'The puritan psychology of valuing money for its own sake, and not for the enjoyments and comforts it might yield, is that of the ideal entrepreneur as he was conceived of in the early days of capitalism' (ibid.: 60). 20. '.. we set out, not to justify or criticise the assumption that entrepreneurs aim at maximising profits, but to make its implications explicit' (ibid.: 60). 
is in effect part and parcel of the overarching strategic aim of defending and ensuring the dominance of the 'hard core.' The two - Micro-foundations and 'hard core' - have become closely intertwined, and the orientating and disciplining role of the latter is of crucial importance in driving the former.

The two most obvious objections to the 'Micro-foundations' project take the form of what King (2012) calls the 'principle of downward causation' and the 'fallacy of composition' argument. The first objection - 'downward causation' - claims that the 'whole' can have a significant impact on the behavior of the 'parts'; the second objection - the 'fallacy of composition' - claims that the 'whole' is more than the sum of its parts. By ignoring the 'whole,' therefore, microeconomics may not only be unable to explain the 'whole' but may even not be able to provide a satisfactory explanation for the 'part.'

But, unfortunately, these objections have carried little weight with the economics academic profession. Is it the charm of the Micro-foundations dogma that has proven to be irresistible? Despite the appeal of the Micro-foundations project, we argued in this paper that a probably more compelling reason is to be found in the overwhelming force of the discipline's 'hard core.' Given the micro-theoretical nature of the 'hard core,' the Micro-foundations project and professional respect for the 'hard core' have become closely intertwined and the orientating and disciplining role of the latter is of crucial importance in driving the former. In these circumstances, questioning the Micro-foundations project is tantamount to confronting the 'hard core.' This then leads us to a critical scrutiny of the 'hard core' and its central microeconomic content.

The examination of the two most fundamental tenets of the 'hard core' shows that they are open to criticism and suffer from serious weaknesses. Maximization of utility is not only contradicted by a lot of experimental and other empirical evidence but it is also neither necessary nor sufficient for establishing the 'law' of demand. Profit maximization is also found wanting both on theoretical and empirical grounds, in the case of large corporations under managerial control. Profit maximization is also inconsistent or implausible in the case of small owner-run firms. These are serious failings, which should weaken confidence in the relevance and robustness of 'positive' microeconomic theory. Consequently, privileging micro over macro theory does not ensure sound foundations and the relationship between microeconomics and macroeconomics is better captured by and more fruitfully analysed in terms of the bridge metaphor proposed by King (2012).

\section{REFERENCES}

Al-Najjar, N., Baliga, S., Besanko, D. (2008): Market forces meet behavioral biases: cost misallocation and irrational pricing, in: Rand Journal of Economics, 39(1), 214-237.

Arestis, P. (1992): The Post-Keynesian Approach to Economics: An Alternative Analysis of Economic Theory and Policy, Aldershot, UK: Edward Elgar.

Baumol, W.J. (1959): Business Behaviour, Value and Growth, London and New York: Macmillan. (Revised edn, New York: Harcourt, Brace and World, 1967.)

Becker, G.S. (1962): Irrational behavior and economic theory, in: Journal of Political Economy, 70(1), 1-13.

Berle, A., Means, G. (1932): The Modern Corporation and Private Property, New Brunswick, NJ: Transaction Publishers. (2nd edn, New York: Harcourt, Brace and World, 1967).

Blaug, M. (1980): The Methodology of Economics, Cambridge, UK, New York and Melbourne: Cambridge University Press.

Boland, L.A. (1981): On the futility of criticizing the neoclassical maximization hypothesis, in: American Economic Review, 71, 1031-1036.

Camerer, C.F., Loewenstein, G., Rabin, M. (2004): Advances in Behavioral Economics, Princeton, NJ: Princeton University Press. 
Cyert, R.M., March, J.G. (1963): A Behavioral Theory of the Firm, Englewood Cliffs, NJ: Prentice-Hall.

Davidson, P. (1977): Money and general equilibrium, in: Economie Apliquee, 30(4), 541-563.

De Scitovszky, T. (1943): A note on profit maximization and its implications, in: Review of Economic Studies, 11(1), 57-60.

Eichner, A.S. (1976): The Megacorp and Oligopoly: Micro Foundations of Macro Dynamics, Cambridge, UK: Cambridge University Press.

Fisher, F.M. (1969): The existence of aggregate production functions, in: Econometrica, 37(4), 553-577.

Friedman, M. (1953): Essays in Positive Economics, Chicago: University of Chicago Press.

Hall, R., Hitch, C. (1939): Price theory and business behaviour, in: Oxford Economic Papers, 2, 12-45.

Hartley, J.E. (1997): The Representative Agent in Macroeconomics, London and New York: Routledge.

Hildenbrand, W. (1994): Market Demand: Theory and Empirical Evidence, Princeton, NJ: Princeton University Press.

Kahneman, D., Tversky, A. (1979): Prospect theory: an analysis of decision under risk, in: Econometrica, 47(2), 263-291.

Kahneman, D., Tversky, A. (1982): The psychology of preferences, in: Scientific American, 246(1), $160-173$.

King, J.E. (2012): The Microfoundations Delusion: Metaphor and Dogma in the History of Macroeconomics, Cheltenham, UK and Northampton, MA: Edward Elgar.

Kirman, A.P. (1992): Whom or what does the representative individual represent?, in: Journal of Economic Perspectives, 6(2), 117-136.

Lakatos, I. (2001): The Methodology of Scientific Research Programmes, Cambridge, UK: Cambridge University Press.

Latsis, S.J. (1976): Method and Appraisal in Economics, Cambridge, UK: Cambridge University Press.

Marris, R. (1963): A model of the managerial enterprise, in: Quarterly Journal of Economics, 77, 185-209.

Marris, R. (1964): Theory of 'Managerial' Capitalism, London: Macmillan.

Mishan, E.J. (1961): Theories of consumer's behaviour: a cynical view, in: Economica, 28, 1-11.

Nagel, E. (1963): Assumptions in economic theory, in: American Economic Review, 53(2), 211-219.

Rizvi, S.A.T. (2006): The Sonnenschein-Mantel-Debreu results after thirty years, in: History of Political Economy, 38, 228-245.

Schumpeter, J.A. (1954): History of Economic Analysis, London: Allen and Unwin.

Simon, H. (1955): A behavioral model of rational choice, in: Quarterly Journal of Economics, 69(1), 99-118.

Simon, H. (1959): Theories of decision-making in economics and behavioral science, in: American Economic Review, 49, 253-283.

Simon, H. (1964): On the concept of organizational goal, in: Administrative Science Quarterly, 9, 1-22.

Skouras, T. (1980): The tools of demand and supply: good for an economist or a parrot?, in: Freris, A., Skouras, T., 'Against Demand and Supply: Two Essays,' Thames Papers in Political Economy, Summer.

Stigler, G.J. (1950): Development of Utility Theory II, in: Journal of Political Economy, 58(5), 373-396.

Weintraub, S. (1956): A Macroeconomic Approach to the Theory of Wages, Durham, NC: Duke University Press.

Williamson, O.E. (1963): Managerial discretion and business behavior, in: American Economic Review, 53, 1032-1057.

Williamson, O.E. (1964): The Economics of Discretionary Behavior, Englewood Cliffs, NJ: PrenticeHall. 